\title{
Primary cilia in energy balance signaling and metabolic disorder
}

\author{
Hankyu Lee, Jieun Song, Joo Hyun Jung \& Hyuk Wan Ko ${ }^{*}$ \\ College of Pharmacy, Dongguk University, Goyang 10326, Korea
}

Energy homeostasis in our body system is maintained by balancing the intake and expenditure of energy. Excessive accumulation of fat by disrupting the balance system causes overweight and obesity, which are increasingly becoming global health concerns. Understanding the pathogenesis of obesity focused on studying the genes related to familial types of obesity. Recently, a rare human genetic disorder, ciliopathy, links the role for genes regulating structure and function of a cellular organelle, the primary cilium, to metabolic disorder, obesity and type II diabetes. Primary cilia are microtubule based hair-like membranous structures, lacking motility and functions such as sensing the environmental cues, and transducing extracellular signals within the cells. Interestingly, the subclass of ciliopathies, such as Bardet-Biedle and Alström syndrome, manifest obesity and type II diabetes in human and mouse model systems. Moreover, studies on genetic mouse model system indicate that more ciliary genes affect energy homeostasis through multiple regulatory steps such as central and peripheral actions of leptin and insulin. In this review, we discuss the latest findings in primary cilia and metabolic disorders, and propose the possible interaction between primary cilia and the leptin and insulin signal pathways which might enhance our understanding of the unambiguous link of a cell's antenna to obesity and type II diabetes. [BMB Reports 2015; 48(12): 647-654]

\section{INTRODUCTION}

Although metabolic disorders such as obesity and type II diabetes are increasingly global pandemic, their pathophysiology and molecular basis is not completely understood (1). Obesity is defined by excessive fat deposition in our body, predisposing to many diseases. The major culprit for obesity is quite

${ }^{*}$ Corresponding author. Tel: +82-31-961-5224; Fax: +82-31-9615206; E-mail: kohw@dongguk.edu

http://dx.doi.org/10.5483/BMBRep.2015.48.12.229

Received 4 November 2015

Keywords: Ciliogenesis, Ciliopathy, Insulin, Leptin, Obesity, Primary cilia complex, due to many confounding genetics and environmental factors equivocally affecting the progress of the disease. Moreover, metabolic disorders are interrelated diseases exemplified by the association of obesity with insulin resistance, leading to development of type II diabetes (2). Genetic factors for obesity are poorly understood, and recent progress by genome-wide association studies support the notion of polygenic features of obesity which suggests that multiple genes, tissues and pathways contribute to the disease $(3,4)$. Intriguing subset of genes associated with obesity cause a dysfunction of primary cilia, which results in a rare pleiotropic human disorder called ciliopathy $(5,6)$. Primary cilia are microtubule based cellular organelles protruding 1 to 50 micrometer from the apical surface of cell membrane; they are considered as cellular antenna due to their function, as perceiving the sensory cues or processing the extracellular signaling which are important for cell functions (7). Genetic mutations causing disruption of ciliary structure or function are responsible for multiple congenital disorders in humans (6). Most of the primary cilia in mammals follow the rule of one cilium per cell; they are dynamic organelles because multiple regulatory steps are involved in ciliogenesis in a cell cycle dependent manner. Considering the size of ciliary genes in genome (which are predicted to about more than 1000 ciliary genes), more than 127 disorders currently share common clinical features of ciliopathies, and the list of confirmed ciliopathies will rapidly increase in the near future (8). Nonetheless, the direct association of obesity with ciliopathies are interestingly very limited to a couple of subtypes of ciliopathies, namely Bardet-Biedle and Alström syndrome (9). Although recent studies from mouse model system and human genetic studies are corroborating the link between cilia and obesity, we still need to be cautious on how extensively the primary cilia are involved in the pathogenesis of obesity.

Here, we overview the current updated literatures regarding the dysfunction of primary cilia affecting energy homeostasis in mouse model system or human. We also provide the possible link of primary cilia into key energy balance signaling pathways, leptin and insulin. We would like to highlight that better understanding of the role of primary cilia in regulating energy balance signaling might open a new avenue to treat globally prevalent obesity originating from an unexpected and vestigial ancient organelle, the primary cilia.

ISSN: 1976-670X (electronic edition)

Copyright (C) 2015 by the The Korean Society for Biochemistry and Molecular Biology

(c) This is an open-access article distributed under the terms of the Creative Commons Attribution Non-Commercial License (http://creativecommons.org/licenses/by-nc/4.0) which permits unrestricted non-commercial use, distribution, and reproduction in any medium, provided the original work is properly cited. 


\section{PRIMARY CILIA AND CILIOPATHIES}

Primary cilia are made of nine pairs of microtubule doublets, growing from the centrosome-derived basal body toward the outside of cell membrane, forming an elongated rod shape structure called axoneme which is encapsulated by a specialized cellular membrane (7). Ciliary membrane is continuous with cytoplasmic membrane, but its composition is unique by containing particular forms of phosphoinositides $\left.\mathrm{Pl}_{4,5}\right) \mathrm{P}_{2}$, which are important for ciliary functions (10). Due to the dual recycling function of centrosome, as a basal body for cilia formation, and in cell division for spindle pole body, cilia show dynamic changes in form by assembling or disassembling the axoneme and ciliary membrane during quiescent $\left(\mathrm{G}_{0} / \mathrm{G}_{1}\right)$ or mitotic (M) phase (7). Assembling of cilia (ciliogenesis), requires highly ordered processes which start with the migration and docking of centrioles to the apical surface of membrane of the cells, triggering polymerization of tubulins from the base with the coordinated growth of ciliary membrane (11). To supply substances required for cilia extension in the growing tips, specialized cilia transport system, intraflagellar transports (IFTs) and motor proteins, are needed. Briefly, motor-driven bi-directional movement of the IFT protein complex transports the cargo proteins from the base to the growing tip, or vice versa. Directional movements of the two groups of transport protein complex, IFT A and B, are differently driven by two motor proteins, kinesin-II for anterograde IFT B, and cytoplasmic dynein for retrograde IFT A, respectively. Balanced transport systems are important for ciliogenesis and dysfunction of these causes abnormal cilia formation (12).

An interesting feature of cilia is compartmentalization of cilia from the base to the tip, implying functional specialization of ciliary subdomains (11). The ciliary axoneme nucleates from the base of mother centriole which consists of triplet microtubules, and distinguishable extra structures: the distal and subdistal appendage (DA and SDA) (13). Fibrous DA and SDA become mature form of the structure, with transition fibers forming a barrier from the cytosol compartment after docking onto the apical surface of membrane. At the base of cilia, the microtubule structure shifts to a doublet from the triplet after the transition fiber, and continues with necklace and Y-shaped structure which connects microtubule to the ciliary membrane. The doublet microtubule in proximal region to basal body between transition fiber and Y-shaped necklace are called the transition zone (TZ) which is the most important subdomain for ciliary gating control for cargoes and function. Recently, many protein complexes in transition fibers and TZ are identified as forming function module, and mutation in each complex gene shares identical phenotypes in animal model and humans, supporting the notion that they group together to participate in the specific function (14). TZ continues with the axoneme and the distal end of cilia tip which functions as the signaling center and is important for ciliary signaling flux. Human congenital disruption of ciliary structure or function causes pleiotropic developmental disorders with a variable degree of spectrum, and collectively they are called ciliopathies. More than a dozen diseases, including Bardet-Biedl syndrome (BBS), nephronophthisis (NPHP), Senior-Løken syndrome (SNLS), Alström syndrome (ALMS), Meckel syndrome (MKS), Joubert syndrome (JBTS), oral-facial-digital syndrome type I (OFD 1), Jeune asphyxiating thoracic dystrophy (JATD), Ellis-van Creveld syndrome (EVC), MORM syndrome and Leber congenital amaurosis (LCA), are attributed to cilia formation or function defects and affect most of the organs such as kidney, brain, limb, eye, ear, liver and bone (6). The distinct pathologic features of ciliopathy patient are cystic kidney, skeletal malformation, laterality and cerebral abnormalities. The unique characteristic entities of ciliopathies show wide phenotypic spectrums which are determined by degree of affected cilia and tissue specificity. The degree of ciliopathy symptoms is highly dependent on the identity of the affected gene and its role in ciliogenesis and ciliary function. Moreover, a certain group of ciliopathy genes forming the same ciliary subdomain module

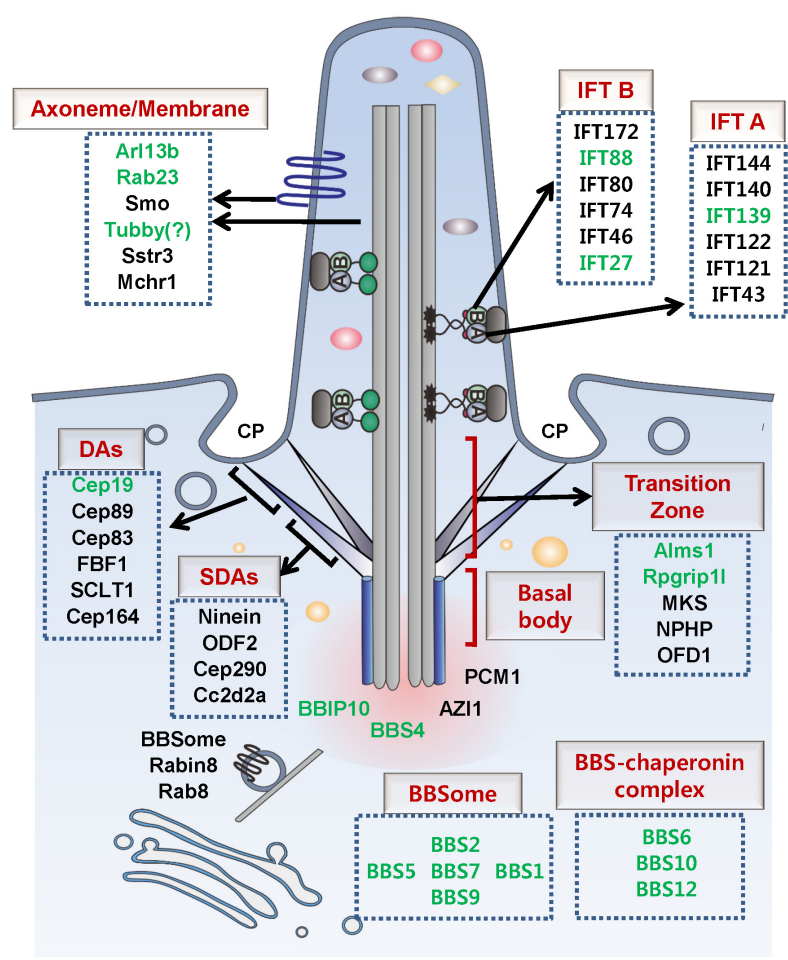

Fig. 1. Ciliary genes associated with obesity. Primary cilia contain several compartments such as basal body, transition fiber (including subdistal appendage (SDA)), and distal appendage (DA), transition zone, and axoneme. Each compartment plays a specific function to regulate the import and export of cargoes and transport proteins such as IFT B and A. Currently, studies from the mouse model system and humans show that disruption of multiple ciliary genes (green) maintaining cilia structure and function manifest obesity phenotypes. 
Table 1. List of proteins in animal model system or humans, showing obesity involved in ciliogenesis or ciliary function

\begin{tabular}{|c|c|c|c|c|}
\hline Gene & Murine mutation & Murine phenotype & Human phenotype & $\begin{array}{c}\text { Ciliary } \\
\text { localization }\end{array}$ \\
\hline ALMS1 & Alms $1^{\text {foz }}$ & $\begin{array}{l}\text { Retinal dysfunction, hearing loss, obesity, } \\
\text { hyperinsulinemia, male-specific hyperglycemia, } \\
\text { hypogonadism }\end{array}$ & $\begin{array}{l}\text { Short stature, wide feet, retinal degeneration, } \\
\text { hearing loss, mental retardation, hypothyroidism, } \\
\text { truncal obesity, t2dm, insulin resistance, hepatic } \\
\text { dysfunction, hyperlipidemia, hypogonadism }\end{array}$ & Transition zone \\
\hline BBS1 & $\mathrm{Bbs} 1^{\mathrm{tm} 1 \mathrm{Vcs}}$ & $\begin{array}{l}\text { Polydactyly, abnormal olfactory sensation, } \\
\text { hydrocephalus, obesity, polycystic kidney }\end{array}$ & $\begin{array}{l}\text { Polydactyly, retinopathy, hypogenitalism, mental } \\
\text { retardation, congenital heart disease, obesity, } \\
\text { diabetes mellitus, hypertension, renal } \\
\text { malformation }\end{array}$ & $\begin{array}{l}\text { Axoneme, Basal } \\
\text { body }\end{array}$ \\
\hline BBS2 & $\mathrm{Bbs} 2^{\mathrm{tm} 1 \mathrm{Vcs}}$ & $\begin{array}{l}\text { Abnormal social interaction, polydactyly, } \\
\text { abnormal brain neuroanatomy, mislocalization of } \\
\text { rhodopsin, obesity, absent sperm flagellar }\end{array}$ & $\begin{array}{l}\text { Developmental delay, polydactyly, retinitis } \\
\text { pigmentosa, obesity, renal gonadal malformation }\end{array}$ & $\begin{array}{l}\text { Axoneme, Basal } \\
\text { body }\end{array}$ \\
\hline BBS3 & $\operatorname{Arl} 6^{\mathrm{tm} 1 \mathrm{Vcs}}$ & $\begin{array}{l}\text { Polydactyly, retinal degeneration, hydrocephalus, } \\
\text { obesity, absent sperm flagellar }\end{array}$ & $\begin{array}{l}\text { Obesity, renal anormalies, reproductive } \\
\text { dysfunction }\end{array}$ & Axoneme \\
\hline BBS4 & $\mathrm{Bbs} 4^{\mathrm{tm} 1 \mathrm{Vcs}}$ & $\begin{array}{l}\text { Embryonic lethality, retinal degeneration, } \\
\text { impaired olfaction, obesity, polyphagia, renal } \\
\text { abnormalities, male infertility }\end{array}$ & $\begin{array}{l}\text { Polydactyly, retinal dystrophy, chronic nasal } \\
\text { congestion, genitourinary malformations, } \\
\text { learning disabilities, obesity, renal anormalies }\end{array}$ & $\begin{array}{l}\text { Basal body, } \\
\text { pericentriolar }\end{array}$ \\
\hline BBS5 & Bbs5 $5^{\mathrm{tm} 1 \mathrm{~b}(\mathrm{EUCOMM}) \mathrm{Wtsi}}$ & $\begin{array}{l}\text { Skeleton dysplasia, retina dysplasia, obesity, } \\
\text { thrombocytopenia }\end{array}$ & $\begin{array}{l}\text { Polydactyly, retinal dystrophy, learning } \\
\text { difficulties, congenital heart disease, obesity, } \\
\text { renal anormalies }\end{array}$ & $\begin{array}{l}\text { Axoneme, Basal } \\
\text { body, Membrane }\end{array}$ \\
\hline BBS6 & $\mathrm{Mkks}^{\mathrm{tm} 1 \mathrm{~V} c \mathrm{~s}}$ & $\begin{array}{l}\text { Decreased aggression, hypoactivity, retinal } \\
\text { degeneration, impaired olfaction, hypertension, } \\
\text { obesity, hyperphagia, absence of flagella }\end{array}$ & $\begin{array}{l}\text { Polydactyly, congenital heart disease, } \\
\text { hydrometrocolpos }\end{array}$ & $\begin{array}{l}\text { Centrosome, Basal } \\
\text { body, Cytoplasm }\end{array}$ \\
\hline BBS7 & $\mathrm{Bbs} 7^{\mathrm{tm} 1 \mathrm{Vcs}}$ & $\begin{array}{l}\text { Retinal degeneration, ventriculomegaly, obesity, } \\
\text { polycystic kidney, lack of spermatozoa flagella }\end{array}$ & $\begin{array}{l}\text { Polydactyly, retinal dystrophy, hypogenitalism, } \\
\text { learning difficulties, obesity, renal abnormalities }\end{array}$ & $\begin{array}{l}\text { Basal body, } \\
\text { Cytoplasm, } \\
\text { Nucleus }\end{array}$ \\
\hline BBS8 & $\mathrm{Ttc}^{\mathrm{tm} 1 \text { Reed }}$ & $\begin{array}{l}\text { Retinal degeneration, impaired olfation, obesity, } \\
\text { renal tubule dilation }\end{array}$ & $\begin{array}{l}\text { Cognitive impairment, polydactyly, retinitis } \\
\text { pigmentosa, situs inversus, obesity }\end{array}$ & $\begin{array}{l}\text { Basal body, } \\
\text { Cytoplasm, Focal } \\
\text { adhesion }\end{array}$ \\
\hline BBS9 & None & None & $\begin{array}{l}\text { Polydactyly, retinal dystrophy, mental retardation, } \\
\text { obesity, renal dysfunction }\end{array}$ & Basal body \\
\hline BBS10 & $\mathrm{Bbs} 10^{-1-}$ & $\begin{array}{l}\text { Retinal degeneration, obesity, hyperphagia, } \\
\text { hyperleptinemia, renal abnormalities }\end{array}$ & $\begin{array}{l}\text { Polydactyly, retinal dystrophy, intellectual } \\
\text { disability, obesity, renal dysfunction, } \\
\text { hypogonadism }\end{array}$ & Basal body \\
\hline BBS12 & Bbs12 $2^{\mathrm{tm} 1.1 V \operatorname{mar}}$ & $\begin{array}{l}\text { Obesity, increased insulin sensitivity, increased } \\
\text { glucose usage, decreased inflammatory response }\end{array}$ & $\begin{array}{l}\text { Myopia, astigmatism, night blindness, retinitis } \\
\text { pigmentosa, hypodontia, obesity }\end{array}$ & $\begin{array}{l}\text { Basal body, } \\
\text { Cytoplasm }\end{array}$ \\
\hline $\begin{array}{l}\text { BBS17 } \\
\text { (LZTFL1) }\end{array}$ & None & None & $\begin{array}{l}\text { Polydactyly, retinal degeneration, polyuria, } \\
\text { polydypsia, obesity, polycystic kidney, } \\
\text { hypogonadism }\end{array}$ & Cytoplasm \\
\hline $\begin{array}{c}\text { BBS18 } \\
\text { (BBIP10) }\end{array}$ & Bbip10 ${ }^{\operatorname{tm} 1.1 G n e}$ & $\begin{array}{l}\text { Postnatal lethality, retinal degeneration, obesity, } \\
\text { hyperphagia, male infertility }\end{array}$ & $\begin{array}{l}\text { Behavioral dysfunction, brachydactyly, visual } \\
\text { impairment, learning difficulties, obesity }\end{array}$ & Axoneme \\
\hline $\begin{array}{l}\text { BBS19 } \\
\text { (IFT27) }\end{array}$ & Ift27 $7^{\text {null1 }}$ & $\begin{array}{l}\text { Polydactyly, abnormal flexure of the wrists, } \\
\text { micrognathia, hypotelorism, omphaloceles, } \\
\text { cyanosis, cardiac malformation, lung isomerisms }\end{array}$ & $\begin{array}{l}\text { Atopy, polydactyly, retinitis pigmentosa, } \\
\text { hypogenitalism, congenital heart disease, } \\
\text { obesity, fatty liver, renal hypoplasia }\end{array}$ & Axoneme \\
\hline Arl13b & Arl13b $b^{h n n}$ & $\begin{array}{l}\text { Left-right randomization, defects of neural } \\
\text { patterning }\end{array}$ & $\begin{array}{l}\text { Retinal anomalies, molar tooth sign, superior } \\
\text { vermian dysgenesis, elongated cerebellar } \\
\text { peduncles, obesity }\end{array}$ & Membrane \\
\hline Cep19 & Cep19 $9^{\mathrm{tm} 2.1 \mathrm{mgi}}$ & $\begin{array}{l}\text { Obesity, hyperphagia, glucose intolerant, insulin } \\
\text { resistant }\end{array}$ & $\begin{array}{l}\text { Intellectual disability, coronary artery disease, } \\
\text { myocardial infarctions, congestive heart failure, } \\
\text { obesity, t2dm, decreased sperm counts. }\end{array}$ & Distal appendage \\
\hline IFT88 & $\operatorname{Tg} 737^{\text {loxP }} ;$ CAGG-Cre ${ }^{E R}$ & $\begin{array}{l}\text { Obesity, hyperphagia, hyperglycemia, } \\
\text { hyperinsulnemia, hyperleptinemia, cystic kidney }\end{array}$ & None & Axoneme \\
\hline INPP5E & Inpp5 $\mathrm{e}^{\mathrm{t} m 15 s c h}$ & $\begin{array}{l}\text { Bilateral anophthalmos, bifid sternum, cleft palate, } \\
\text { hexadactyly, anencephaly or exencephaly, cystic } \\
\text { kidneys }\end{array}$ & $\begin{array}{l}\text { Retinal dystrophy, molar tooth sign, mental } \\
\text { retardation, truncal obesity, micropenis } \\
\text { syndrome }\end{array}$ & Membrane \\
\hline Kif3A & $\begin{array}{l}\text { Kif3a }^{\text {loxP }} \text {; CAGG-Cre }{ }^{\text {ER }} \\
\text { or POMC-Cre }\end{array}$ & $\begin{array}{l}\text { Obesity, hyperphagia, hyperglycemia, } \\
\text { hyperinsulnemia, hyperleptinemia, cystic kidney }\end{array}$ & None & Axoneme \\
\hline Rab23 & Rab23 ${ }^{\mathrm{opb}}$ & Embryonic lethal, polydactyly, open brain & Craniosynostosis, polydactyly, obesity & Axoneme \\
\hline RPGRIP1L & 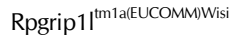 & Obesity, hyperphagia & None & Transition zone \\
\hline Tubby & $\mathrm{Tub}^{\text {tub }}$ & $\begin{array}{l}\text { Retinal degeneration, hearing loss, obesity, } \\
\text { hyperinsulinemia }\end{array}$ & Night blindness, decreased visual acuity, obesity & Axoneme(?) \\
\hline
\end{tabular}


share common clinical features, indicating dedicated biological roles for the each set of ciliary structural modules (15). For example, NPHP module and JBTS module proteins localized in TZ and mutations of these have phenotypically overlapping entities such as cystic kidney disease. However, NPHP primarily manifests in the renal cyst, but JBTS is in retinal degeneration, brain malformation and skeletal defect (16). Interestingly, two subtypes of ciliopathies, BBS and ALMS, are distinctively associated with morbid obesity and type II diabetes in humans (5). These human genetic links of the two types of ciliopathies to metabolic disorders, implicate that the cellular function of cilia might intersect with the energy balance system but lack of possible molecular mechanisms, and a limited type of ciliopathies casts a doubt for the ciliary role for obesity. Multiple lines of evidence have indicated mutations of multiple ciliary subdomain genes in the mouse model system and other human study results in obesity; these results corroborate the ciliary role of obesity, as shown in Fig. 1. Currently, studies on ciliopathies and related mouse model system confirms that disruption of $\sim 20$ cilia-related genes leads to obesity (Table 1) (8). Based on the type, we could subdivide the genes as a group identified in well characterized ciliopathies or a group related to the structure and function of cilia.

\section{CILIOPATHIES RELATED TO OBESITY: BBS AND ALMS}

Bardet-Biedle syndrome (BBS) is a recessive rare genetic disorder $(\sim 1$ in $13,500-160,000)$ which was first reported in 1866 by Laurence and Moon, and later by Bardet and Biedl (17). The clinical phenotype of affected patients commonly displayed obesity, retinal degeneration, polydactyly, cystic kidney, hypogonadism and mental retardation. The genetic basis of BBS is a consequence of ciliary dysfunctions, which are the first examples of the fundamental role of cilia in obesity; 14 genes (BBS1-12, MKS1 and CEP290) have been identified until now (18). The first molecular link of BBS to cilia dysfunction was hinted by a BBS8 patient who had defects in the left-right axis (situs inversus) which is a cardinal feature of ciliopathies. Recently, it has been shown that BBS is known to localize to the basal body (19). Most of the BBS proteins localize to basal bodies or cilia, but mutations in BBS genes do not affect ciliogenesis. Recent progress suggests that BBS proteins form a complex and associate with RAB8 for ciliary membrane growth by trafficking of vesicles to the cilia (20). Direct evidence linking BBS to obesity is coming from studies on mouse model system of BBS 2, 4 and 6 which show increased levels of leptin with unreduced food intake in response to leptin (21). In addition, studies from cultured cells demonstrate that depletion of BBS1 affects leptin receptor trafficking (22). These results indicate that defects in leptin signaling might contribute to obesity in BBS. In contrast, conflicting results regarding role of cilia in leptin signaling have been reported from the Yoder group (23). Although they observed leptin resistance after obese state in BBS4 mutant mice, they interestingly showed that preobese BBS4 mutant mice show normal leptin signaling as well as another cilia mutant, Ift88 (23). These results suggest that cilia involved in leptin resistance and signaling defects might not be the primary cause of obesity in BBS mutants. The precise molecular mechanisms underlying BBS mediated leptin signaling in obesity have not been fully elucidated, and further investigations are needed to resolve the conflicting issue.

Alström syndrome (ALMS) is the second most well studied type of ciliopathy involved in obesity and reported in 1959 by Alstrom (24). ALMS is a very rare recessive monogenic disorder $(\sim 1$ in $10,000-1,000,000)$ manifesting retinal degeneration, hearing loss, cardiomyopathy, childhood obesity and type II diabetes. Although ALMS has many similarities to BBS, it does not manifest mental retardation, polydactyly, and hypogonadism, as seen in BBS. The mutation in ALMS is caused by mutations in the novel gene ALMS1, and the mouse model recapitulated pathologic features in ALMS patients $(25,26)$. ALMS1 is a ubiquitously expressed $461-\mathrm{kDa}$ protein of unknown function and contains novel tandem repeats and putative leucine zipper domain. Phenotypic similarities to BBS suggest that ALMS1 might be related to ciliopathies, and studies from cultured cells show that ALMS1 localizes to basal bodies without affecting ciliogenesis (27). Recent data have been shown that ALMS1 regulates cell migration and endosomal trafficking, but the molecular mechanism of ALMS1 in obesity and cilia remains to be revealed (28).

\section{CILIARY GENES LINK TO OBESITY}

Mice lacking key ciliary genes such as Ift88 and Kif3a, which are key transport proteins for ciliogenesis, show embryonic lethality attributing to multiple defects in developmental signaling (29). Due to lack of studies regarding role for cilia in adult stage, the idea of ciliary role in obesity had been challenged. However, well-designed mouse genetic model studies from bona fide ciliary genes, Ift88 and Kif3a, uphold that idea (30). Using two conditional alleles of Kif3a and Ift88 with neuron or hypothalamic pro-opiomelanocortin-expressing neuronal cells in specific Cre lines, the Yoder group examined the direct effects of adult stage ciliary loss on weight gain without developmental defects (30). Interestingly, they observed that both of the alleles show increasing levels of leptin as well as insulin, with reduced responses. They further showed that the ciliary effect on obesity and type II diabetes are caused by hyperphagic behavior of affected mice rather than secondary effects. These studies indicate that cilia might play a role in the energy balance by affecting the central regulator in the hypothalamus. Growing evidence further provides the possible link of cilia in central energy metabolism regulation with ciliary localization of many G protein-coupled receptors (GPCRs) to regulate GPCR signaling, including melanin-concentrating hormone receptor 1 (MCHR1) and somatostatin receptor 3 (SSTR3) which are well-known for appetite regulation (31). The tubby mouse was originally introduced as a naturally identified obesity ani- 


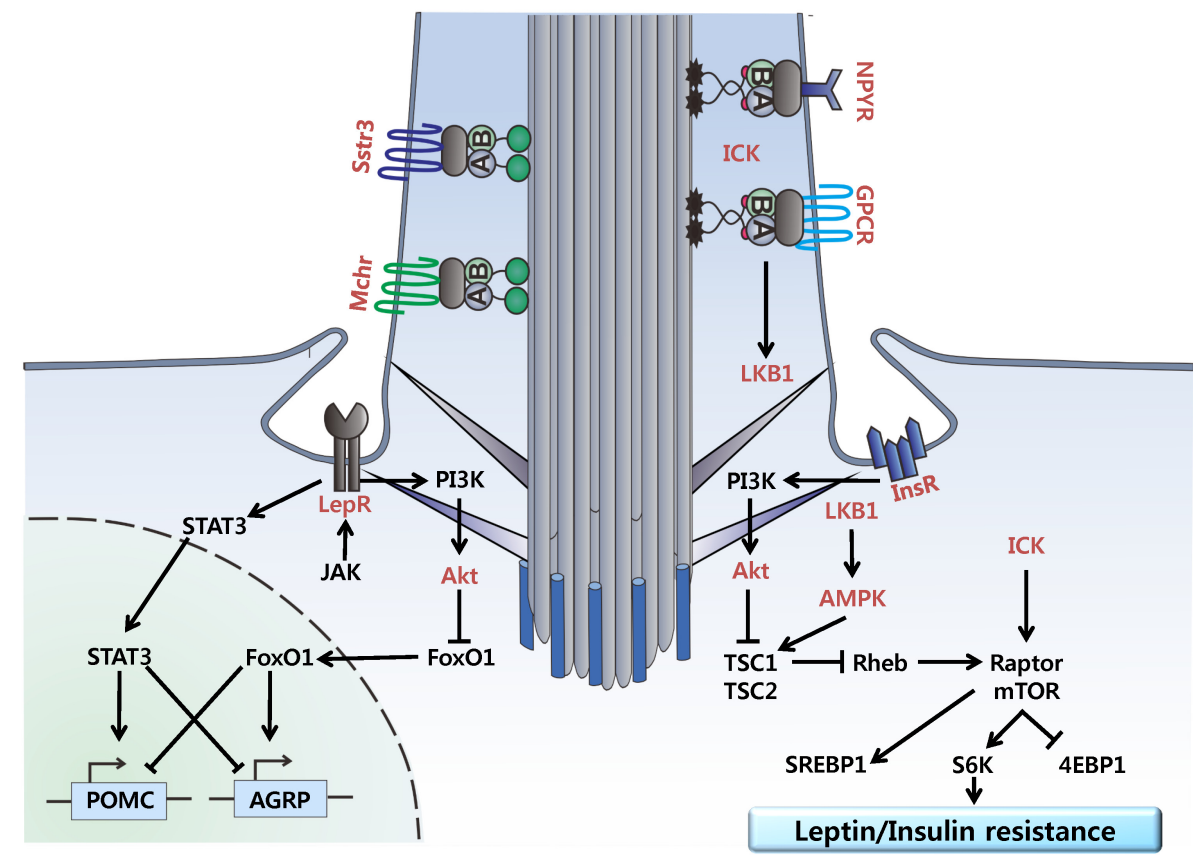

Fig. 2. Energy balance signaling, leptin and insulin interaction with possible ciliary genes. Leptin and insulin ligand binding to their receptors (LepR and InsR) signaling share the PI3K-AKT pathways. LepR activation specifically increases the expression of Pomc through JAK-STAT3 activation, and PI3K-AKT pathway mediated FoxO1 inhibition. Insulin receptor activation shares PI3K-Akt pathway and further regulates mTOR-S6K pathway. S6K inhibition by genetic or pharmacological intervention causes insulin resistance. Primary cilia related downstream signal transduction mediators of leptin and insulin are highlighted with red color. mal model with spontaneous loss of function of the tubby gene, displaying retinal degeneration, hearing loss and late-onset obesity. Recently the molecular basis of it highly links it to ciliary function like GPCR trafficking (Table 1 and Fig. 2) (32). The tubby gene family also includes tubby-like protein 1, 2 and 3 (Tulp1, 2 and 3), and they share the phosphodiesterase binding C-terminal tubby domain. Although Tulp mutant mice do not show obesity, they are involved in the GPCR ciliary trafficking and regulate ciliary signaling. Moreover, specific distribution of phosphoinositide in the ciliary membrane is important for proper protein trafficking in cilia and disruption of its distribution by mutations in inositol polyphosphate 5-phosphatase $\mathrm{E}$ (INPP5E), causing ciliary dysfunction and obesity in humans (Table 1) (33). These findings highlight that the ciliary role of GPCR trafficking and signal transduction in cilia might be related to energy homeostasis. Several lines of human genetic studies consolidate the ciliary role in obesity. Evidences from Arl13b and Rab23 mutation in humans demonstrated that they display canonical phenotypes of ciliopathies with obesity $(34,35)$. CEP19 is a novel centrosomal protein, and mutations in human and mouse model systems cause morbid obesity and resistance to insulin (36). Although Cep19 mainly localizes in the basal bodies, implicating a ciliary role, Cep19 KO mice do not show any noticeable structural abnormality of cilia and common phenotypic features of ciliopathy except obesity. Further studies revealing ciliary function and obesity of Cep19 remain to be revealed.

\section{ROLE OF PRIMARY CILIA IN ENERGY BALANCE SIGNALING: LEPTIN AND INSULIN}

Leptin and insulin are peripheral energy metabolisms, controlling energy homeostatic neuropeptides, proopiomelanocortin (POMC) and agouti-related protein (AGRP) expression. They are secreted by white adipocyte tissues or pancreatic $\beta$-cells respectively, and their primary function is to induce anorexigenic effect (37). Leptin binding to its receptor (LepR-b) recruits and activates Janus kinase (JAK), leading to STAT3 phosphorylation and activation for Pomc and Agrp expression in the hypothalamus (Fig. 2). LepR-b also activates phosphatidylinositol-3-kinase (PI3K) signaling resulting in AKT activation, affecting many downstream targets such as Forkhead box protein O1 (FoxO1), AMP-dependent kinase (AMPK) and mammalian target of rapamycin (mTOR). Insulin signaling by insulin receptor substrate (IRS) also converges with the leptin signaling pathway at the step of activation of PI3K and AKT (Fig. 2). When the energy status changes to surplus, leptin and insulin activate mTOR pathway but inhibit the AMPK activation to suppress food intake.

Primary cilia have been established as the signaling center for processing multiple animal development and homeostasis signaling pathways, Hedgehog $(\mathrm{Hh})$, Notch, Wnt, mTOR and Platelet-derived growth factor receptor $\alpha$ (PDGFR $\alpha)$ (38). Hh signaling has been extensively studied, and primary cilia are highly regarded as critical organelles in transmitting $\mathrm{Hh}$ signaling (39). Briefly, the secreted Sonic hedgehog (Shh) protein in mammals binds to the transmembrane receptor, Patched1 
(Ptch1) to release its inhibition of the GPCR-like protein, Smoothened (Smo), leading to ciliary localization. Ciliary Smo subsequently activates the Gli transcription factors in primary cilia with unknown mechanisms, which turn on the Shh target gene expressions. Although the molecular logic of other signaling pathways are different and dependent on types of signaling, they share common theme with Hh signaling which key elements in signaling accumulate within the cilia to transduce signaling; for example Notch or PDGF receptors and downstream effectors, and loss of cilia, affects the extent of signal transduction.

Recently, several lines of indirect evidences suggest a possible crosstalk between ciliary signaling and energy balance signaling. First, energy homeostatic neuropeptides or neurotransmitter receptors, for example insulin growth factor receptor (IGFR), melanin-concentrating hormone receptor (Mchr) and neuropeptide $Y$ receptor (NPYR), localize to the cilia and require ciliogenesis machinery such as BBS and cilia function to properly transmit signaling (31). The Bbs or Ift mutant mice show reduced Pomc expression with leptin resistance, and LepR interacts with BBS to translocate to the cilia (22). These findings indicate that primary cilia are required for leptin signaling by properly trafficking LepR. However, studies from tamoxifen inducible ablation of Ift88 mice, argues against the contribution of leptin resistance to obesity (23). These observations are not consistent with BBS mutant mice results and need further experiments to clarify them. Second, GPCR signaling cascade in cilia, such as somatostatin receptor 3 (Sstr3), and Mchr increase the levels of cyclic AMP and $\mathrm{Ca}^{2+}$, which in turn, activate various downstream targets; for example LKB1 and AMP-activated protein kinase (AMPK) $(31,40)$. Ciliary localized IGFR also activates the kinase cascade including PI3K-Akt, which could activate the mTOR pathway (37). Absence of cilia might affect the PI3K-Akt axis, resulting in down-regulation of anorexic Agrp expression or suppression of S6 kinase (S6K), causing hyperphagic obesity and leptin/insulin resistance. Third, protein kinases regulating ciliogenesis might involve energy balance signaling through mTOR pathways. Though it happens in kidney tissue culture cells, liver kinase B1 (LKB1) localizes in the cilium, and bending of cilia activates the LKB1 to phosphorylate AMPK at the basal body (41). AMPK pathway has been well known as an energy state sensor, and regulates the metabolic enzymes and glucose uptake. AMPK activation by LKB1 might suppress mTOR pathway, leading to insulin resistance (42). In addition to this, intestinal cell kinase (ICK) is a key cilia length control kinase and localizes in cilia; kinase activity is required for proper ciliary localization (43). ICK has been shown to phosphorylate the mTOR effector Raptor, which activates S6K kinase (44). Collectively, multiple kinases regulating ciliogenesis are associated with the mTOR pathway, which are important for leptin/insulin resistance. Further conclusive studies are needed to dissect whether or not the abnormal ciliogenesis by ciliary kinase defects directly affects the mTOR signaling and metabolic disorders.

\section{CONCLUSION}

Human monogenic obesity studies identify crucial genes underlying the molecular basis of obesity, such as leptin, leptin receptor, melanocortin 4-receptor, and pro-opiomelanocortin. Research on primary cilia have been focused on processing of intracellular signaling during animal development and disease in recent years (45). Given that obesity is the accompanying phenotype in ciliopathies, studying this disorder might further unravel the molecular complexities of metabolic disorders by integrating the signaling events derived from primary cilia. However, studies have just been initiated to link the importance of ciliary structure and function on regulating the energy balance of the body. Many unanswered questions remain to be solved, which would deepen our understanding of primary cilia and metabolic disorders. First, primary cilium is the sole organelle existing as one per cell, but pathogenic mutation of the core ciliary genes show variable phenotypes, including obesity, in multiple tissues and malformation of cilia. Intriguingly, only a small fraction of ciliogenesis genes manifest as obesity. The question arises as to why only certain types of ciliogenesis defects are associated with obesity. Ciliogenesis is a highly ordered, sequential event requiring multiple genes, and evidence reveals that some ciliary genes are also involved in cilia-independent events. It might be possible that obesity associated ciliary genes might have dual functions. In fact, the BBSome complex components, Bbs4 and 6, have cilia independent roles in cell division $(46,47)$. Bbs4 localizes to the spindle body in association with dynactin subunit, and depletion of Bbs4 as well as Bbs6 cause defects in cytokinesis and mitosis. Cell cycle protein, Cdk inhibitor p21 and p27, have been shown that they regulate adipogenesis, and mouse model systems develop obesity by an increase in adipocytes (48). Therefore, it might be possible that subset of ciliary genes involved in the cell cycle, might cause adipogenesis dependent obesity. Second, energy homeostasis are maintained under the control of the central nervous system and the another site of the metabolic regulating organ, the pancreas. Recent studies demonstrate that leptin and insulin resistance in BBS mouse model system contributes to obesity. In addition to this, insulin signaling is affected before the obese phenotype is developed in the pancreas. Primary cilia also regulate adipogenesis through Wnt and Hh signaling. Defects in cilia, as shown in BBS12 KO mice, enhance adipogenesis leading to obesity (49). Controversially, cilia dependent obesity might be a secondary effect resulting from increase of food intake. Preobese Bbs4 KO mice show normal leptin response, and leptin resistance developed after mice get obese (23). Overall, these results implicate that primary cilia in central and peripheral metabolic regulators differentially act on development of obesity. We would like to highlight that there are more implications of the role of primary cilia in obesity, and further expanded studies would clarify the role of this tiny cellular organelle in obesity. 


\section{ACKNOWLEDGEMENTS}

This research was supported by Korea Mouse Phenotyping Project (NRF-2014M3A9D5A01073969) of the Ministry of Science, ICT and Future Planning through the National Research Foundation to H.W.K.

\section{REFERENCES}

1. Abelson P and Kennedy D (2004) The obesity epidemic. Science 304, 1413

2. Spiegelman BM and Flier JS (2001) Obesity and the regulation of energy balance. Cell 104, 531-543

3. Meyre D, Delplanque J, Chevre JC et al (2009) Genomewide association study for early-onset and morbid adult obesity identifies three new risk loci in European populations. Nat Genet 41, 157-159

4. Speliotes EK, Willer CJ, Berndt SI et al (2010) Association analyses of 249,796 individuals reveal 18 new loci associated with body mass index. Nat Genet 42, 937-948

5. Sen Gupta P, Prodromou NV and Chapple JP (2009) Can faulty antennae increase adiposity? The link between cilia proteins and obesity. J Endocrinol 203, 327-336

6. Hildebrandt F, Benzing T and Katsanis N (2011) Ciliopathies. N Engl J Med 364, 1533-1543

7. Ko HW (2012) The primary cilium as a multiple cellular signaling scaffold in development and disease. BMB Rep 45, 427-432

8. Badano JL, Mitsuma N, Beales PL and Katsanis N (2006) The ciliopathies: an emerging class of human genetic disorders. Annu Rev Genomics Hum Genet 7, 125-148

9. Mutch DM and Clement K (2006) Unraveling the genetics of human obesity. PLoS Genet 2, e188

10. Reiter JF and Mostov K (2006) Vesicle transport, cilium formation, and membrane specialization: the origins of a sensory organelle. Proc Natl Acad Sci U S A 103, 1838318384

11. Reiter JF, Blacque OE and Leroux MR (2012) The base of the cilium: roles for transition fibres and the transition zone in ciliary formation, maintenance and compartmentalization. EMBO Rep 13, 608-618

12. Ishikawa $\mathrm{H}$ and Marshall WF (2011) Ciliogenesis: building the cell's antenna. Nat Rev Mol Cell Biol 12, 222-234

13. Veleri S, Manjunath SH, Fariss RN et al (2014) Ciliopathyassociated gene $\mathrm{Cc} 2 \mathrm{~d} 2 \mathrm{a}$ promotes assembly of subdistal appendages on the mother centriole during cilia biogenesis. Nat Commun 5, 4207

14. Garcia-Gonzalo FR, Corbit KC, Sirerol-Piquer MS et al (2011) A transition zone complex regulates mammalian ciliogenesis and ciliary membrane composition. Nat Genet 43, 776-784

15. Zaghloul NA and Katsanis N (2010) Functional modules, mutational load and human genetic disease. Trends Genet 26, $168-176$

16. Sang L, Miller JJ, Corbit KC et al (2011) Mapping the NPHP-JBTS-MKS protein network reveals ciliopathy disease genes and pathways. Cell 145, 513-528

17. Laurence JZ and Moon RC (1995) Four cases of "retinitis pigmentosa" occurring in the same family, and accom- panied by general imperfections of development. 1866 . Obes Res 3, 400-403

18. M'Hamdi O, Ouertani $\mathrm{I}$ and Chaabouni-Bouhamed $\mathrm{H}$ (2014) Update on the genetics of bardet-biedl syndrome. Mol Syndromol 5, 51-56

19. Ansley SJ, Badano JL, Blacque OE et al (2003) Basal body dysfunction is a likely cause of pleiotropic Bardet-Biedl syndrome. Nature 425, 628-633

20. Nachury MV, Loktev AV, Zhang Q et al (2007) A core complex of BBS proteins cooperates with the GTPase Rab8 to promote ciliary membrane biogenesis. Cell 129, 1201-1213

21. Rahmouni K, Fath MA, Seo S et al (2008) Leptin resistance contributes to obesity and hypertension in mouse models of Bardet-Biedl syndrome. J Clin Invest 118, 1458-1467

22. Seo S, Guo DF, Bugge K, Morgan DA, Rahmouni K and Sheffield VC (2009) Requirement of Bardet-Biedl syndrome proteins for leptin receptor signaling. Hum Mol Genet 18, 1323-1331

23. Berbari NF, Pasek RC, Malarkey EB et al (2013) Leptin resistance is a secondary consequence of the obesity in ciliopathy mutant mice. Proc Natl Acad Sci U S A 110, 77967801

24. Alstrom $\mathrm{CH}$, Hallgren $\mathrm{B}$, Nilsson $\mathrm{LB}$ and Asander $\mathrm{H}$ (1959) Retinal degeneration combined with obesity, diabetes mellitus and neurogenous deafness: a specific syndrome (not hitherto described) distinct from the LaurenceMoon-Bardet-Biedl syndrome: a clinical, endocrinological and genetic examination based on a large pedigree. Acta Psychiatr Neurol Scand Suppl 129, 1-35

25. Collin GB, Marshall JD, Ikeda A et al (2002) Mutations in ALMS1 cause obesity, type 2 diabetes and neurosensory degeneration in Alstrom syndrome. Nat Genet 31, 74-78

26. Hearn T, Renforth GL, Spalluto C et al (2002) Mutation of ALMS1, a large gene with a tandem repeat encoding 47 amino acids, causes Alstrom syndrome. Nat Genet 31, 79-83

27. Hearn T, Spalluto C, Phillips VJ et al (2005) Subcellular localization of ALMS1 supports involvement of centrosome and basal body dysfunction in the pathogenesis of obesity, insulin resistance, and type 2 diabetes. Diabetes 54, 1581-1587

28. Collin GB, Marshall JD, King BL et al (2012) The Alstrom syndrome protein, ALMS1, interacts with alpha-actinin and components of the endosome recycling pathway. PLoS One 7, e37925

29. Huangfu D, Liu A, Rakeman AS, Murcia NS, Niswander L and Anderson KV (2003) Hedgehog signalling in the mouse requires intraflagellar transport proteins. Nature 426 , 83-87

30. Davenport JR, Watts AJ, Roper VC et al (2007) Disruption of intraflagellar transport in adult mice leads to obesity and slow-onset cystic kidney disease. Curr Biol 17, 15861594

31. Berbari NF, Lewis JS, Bishop GA, Askwith CC and Mykytyn K (2008) Bardet-Biedl syndrome proteins are required for the localization of $G$ protein-coupled receptors to primary cilia. Proc Natl Acad Sci U S A 105, 4242-4246

32. Mukhopadhyay S and Jackson PK (2013) Cilia, tubby 
mice, and obesity. Cilia 2, 1

33. Jacoby M, Cox JJ, Gayral S et al (2009) INPP5E mutations cause primary cilium signaling defects, ciliary instability and ciliopathies in human and mouse. Nat Genet 41, 1027-1031

34. Thomas S, Cantagrel V, Mariani L et al (2015) Identification of a novel ARL13B variant in a Joubert syndrome- affected patient with retinal impairment and obesity. Eur J Hum Genet 23, 621-627

35. Jenkins D, Seelow D, Jehee FS et al (2007) RAB23 mutations in Carpenter syndrome imply an unexpected role for hedgehog signaling in cranial-suture development and obesity. Am J Hum Genet 80, 1162-1170

36. Shalata A, Ramirez MC, Desnick RJ et al (2013) Morbid obesity resulting from inactivation of the ciliary protein CEP19 in humans and mice. Am J Hum Genet 93, 10611071

37. Varela L and Horvath TL (2012) Leptin and insulin pathways in POMC and AgRP neurons that modulate energy balance and glucose homeostasis. EMBO Rep 13, 10791086

38. Zimmerman K and Yoder BK (2015) SnapShot: Sensing and Signaling by Cilia. Cell 161, 692-692 e1

39. Eggenschwiler JT and Anderson KV (2007) Cilia and developmental signaling. Annu Rev Cell Dev Biol 23, 345-373

40. Collins SP, Reoma JL, Gamm DM and Uhler MD (2000) LKB1, a novel serine/threonine protein kinase and potential tumour suppressor, is phosphorylated by cAMP-dependent protein kinase (PKA) and prenylated in vivo. Biochem J 345 Pt 3, 673-680

41. Boehlke C, Kotsis F, Patel V et al (2010) Primary cilia reg- ulate mTORC1 activity and cell size through Lkb1. Nat Cell Biol 12, 1115-1122

42. Zick Y (2005) Ser/Thr phosphorylation of IRS proteins: a molecular basis for insulin resistance. Sci STKE 2005, pe4

43. Moon H, Song J, Shin JO et al (2014) Intestinal cell kinase, a protein associated with endocrine-cerebro-osteodysplasia syndrome, is a key regulator of cilia length and Hedgehog signaling. Proc Natl Acad Sci U S A 111, 8541-8546

44. Wu D, Chapman JR, Wang L et al (2012) Intestinal cell kinase (ICK) promotes activation of mTOR complex 1 (mTORC1) through phosphorylation of Raptor Thr-908. J Biol Chem 287, 12510-12519

45. Farooqi IS and O'Rahilly S (2005) Monogenic obesity in humans. Annu Rev Med 56, 443-458

46. Kim JC, Badano JL, Sibold S et al (2004) The Bardet-Biedl protein BBS4 targets cargo to the pericentriolar region and is required for microtubule anchoring and cell cycle progression. Nat Genet 36, 462-470

47. Kim JC, Ou YY, Badano JL et al (2005) MKKS/BBS6, a divergent chaperonin-like protein linked to the obesity disorder Bardet-Biedl syndrome, is a novel centrosomal component required for cytokinesis. J Cell Sci 118, 1007-1020

48. Naaz A, Holsberger DR, Iwamoto GA, Nelson A, Kiyokawa $\mathrm{H}$ and Cooke PS (2004) Loss of cyclin-dependent kinase inhibitors produces adipocyte hyperplasia and obesity. FASEB J 18, 1925-1927

49. Marion V, Mockel A, De Melo C et al (2012) BBS-induced ciliary defect enhances adipogenesis, causing paradoxical higher-insulin sensitivity, glucose usage, and decreased inflammatory response. Cell Metab 16, 363-377 